\title{
Effect of environmental temperatures on oxygen consumption in infants with congenital disease of the heart
}

\author{
C. T. Kappagoda and F. J. Macartney ${ }^{1}$ \\ From Cardiovascular Unit, University of Leeds; and Department of Paediatric Cardiology, Killingbeck \\ Hospital, Leeds
}

The effect of changes in environmental temperature on the oxygen consumption in babies with congenital disease of the heart has been studied and it has been shown that an inverse relation exists between those two variables.

The significance of these findings on the practice of calculating systemic and pulmonary blood flow jrom predicted values of oxygen consumption is discussed.

There have been several studies on the influence of environmental temperature on oxygen consumption of normal and premature infants (e.g. Hey, 1969). There are, however, no comparable data on the effect of environmental temperature in infants with congenital diseases of the heart. The demonstration of such an effect would undoubtedly have considerable clinical significance because of its influence on the calculation of haemodynamic data. This paper presents the results of an investigation into this problem on a small sample of these infants.

\section{Methods}

This study was conducted on 6 babies with congenital defects of the heart and on 5 babies who were clinically normal. All the babies were investigated in the first month of life. The relevant clinical details are given in the Table. The babies were investigated while asleep in an incubator (Oxygenaire Mk III) approximately 1 hour after a feed. They were clothed in a nappy and a vest and no sedatives were administered.

The oxygen consumption was measured by an open circuit method which has been described in detail previously (Kappagoda and Linden, 1972; Kappagoda et al., 1973). A Perspex hood was placed inside the incubator and positioned over the head of the patient. The hood was connected to the rest of the apparatus through the canopy of the incubator as shown in Fig. 1.

Received 7 July 1975.

1Present address: The Hospital for Sick Children, Great Ormond Street, London WCIN 1EH.
TABLE Details of babies investigated

\begin{tabular}{|c|c|c|c|}
\hline $\begin{array}{l}\text { Initials and } \\
\text { sex of babies }\end{array}$ & Age (wk) & $W t(k g)$ & Diagnosis \\
\hline \multicolumn{4}{|c|}{$\begin{array}{l}\text { Babies with } \\
\text { congenital diseases } \\
\text { of the heart }\end{array}$} \\
\hline $\begin{array}{l}\text { C.C. (M) } \\
\text { M.C. (M) }\end{array}$ & $\begin{array}{l}2 \\
3\end{array}$ & $\begin{array}{l}3 \cdot 2 \\
2 \cdot 5\end{array}$ & $\begin{array}{l}\text { Ebstein's anomaly } \\
\text { Tricuspid atresia } \\
\text { and transposition }\end{array}$ \\
\hline A.D. (F) & 4 & $2 \cdot 3$ & Coarctation of aorta \\
\hline L.H. (M) & 3 & $2 \cdot 85$ & $\begin{array}{l}\text { Tricuspid atresia } \\
\text { and ventricular } \\
\text { septal defect }\end{array}$ \\
\hline C.T. (M) & 3 & $2 \cdot 5$ & Transposition \\
\hline A.C. $(F)$ & 3 & 3.6 & $\begin{array}{l}\text { Transposition and } \\
\text { persistent ductus } \\
\text { arteriosus }\end{array}$ \\
\hline
\end{tabular}

Normal babies

\begin{tabular}{lll} 
Normal babies & & 3.5 \\
J.F. (M) & 2 & 3.2 \\
J.A. (M) & 2 & 3.8 \\
A.J. (F) & 2 & 2.9 \\
J.B. (F) & 1 & $4 \cdot 0$ \\
M.W. (M) & 1 & \\
\hline
\end{tabular}

Air was drawn through the hood by means of the pump P (Type SA 37; Service Electronic Co. Ltd., Stanmore, Middlesex) and collected in the spirometer for a period of $45 \mathrm{~s}$. The patient extracted oxygen from the stream of air as it passed through the hood. The gas collected in the spirometer was then pumped into a paramagnetic oxygen analyser (OA 137; Servomex Controls Ltd., Crowborough, Sussex) which was modified as described by Kappagoda and Linden (1972). The oxygen consumption was calculated as follows: 




FIG. 1 Diagram of apparatus. The baby lies on the mattress of the incubator. A hood is placed inside the canopy and positioned over the head. $P$-pump which draws a stream of air through the hood; S-spirometer; $A$-oxygen analyser; $R$ and $T$ denote telethermometers for recording rectal and environmental (i.e. incubator) temperatures, respectively.

Volume of air drawn through the hood at STPD $=$ $\mathrm{V}$ litre/min.

The concentration of oxygen in room air $=X$ per cent.

The concentration of oxygen in the gas in the spirometer $=\mathrm{Y}$ per cent.

The oxygen consumption $=\mathrm{V} \times\left[\frac{\mathrm{X}-\mathrm{Y}}{100}\right] 1 / \mathrm{min} \mathrm{STPD}$.

During each investigation, the electrocardiogram, respirations, and the rectal temperature were monitored continuously (Kappagoda et al., 1973). For the purpose of this study the environmental temperature was taken as the temperature measured $12.7 \mathrm{~cm}$ above the centre of of the platform of the incubator (British Standards Institution-as quoted by Hey and Mount, 1967). All the temperatures were measured using a telethermometer (Yellow Springs Instrument Corporation, Ohio).

Since this method of measuring oxygen consumption involved drawing a large volume of air $(80-100 \mathrm{l} / \mathrm{min})$ through the incubator, preliminary studies (not reported here) were undertaken which established that this method of measuring oxygen consumption did not result in changes in the 'environmental' temperature, i.e. temperature within the incubator. An example of this aspect of the study is shown in Fig. 2.

\section{Experimental protocol}

After each baby was comfortably settled and asleep in the incubator the oxygen consumption was measured four or five times at each of two or three environmental temperatures. Each baby was maintained at a given temperature for 25 to 45 minutes for 'equilibration' before the measurement of oxygen consumption. The humidity setting on the incubator was unchanged throughout the study. The range of temperatures over which the study was conducted was 23 to $31^{\circ} \mathrm{C}$.

Both parents of each baby were consulted and their permission obtained before the investigation.

\section{Results}

All the babies were asleep during the study and the variations in environmental (i.e. incubator) temperatures were not accompanied by any significant changes in their rectal temperatures $\left(<0.5^{\circ} \mathrm{C}\right)$. The corresponding variations noted in the heart rates and respiratory rates were also relatively small, the largest variations recorded during the entire in-

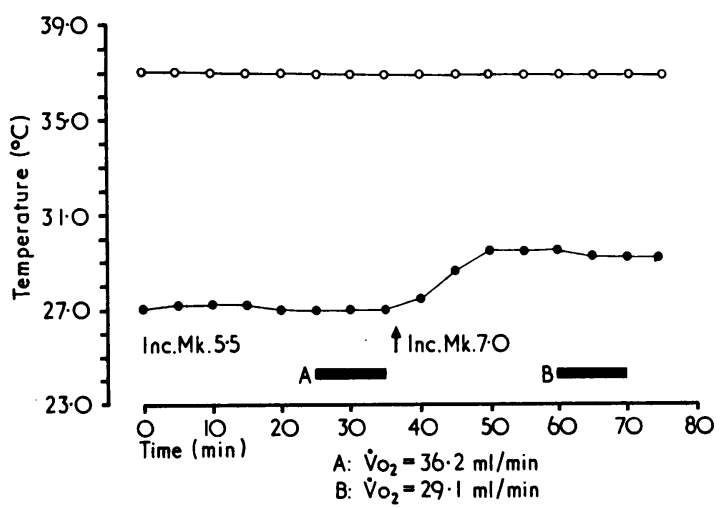

FIG. 2 Effect of a change in environmental temperature on oxygen consumption in a child with congenital heart disease. Ordinate-environmental (i.e. incubator) temperature $-\left({ }^{\circ} \mathrm{C}\right)$ and rectal temperature $\mathrm{O}\left({ }^{\circ} \mathrm{C}\right)$. Abscissa-time ( $m i n)$. The bars ( $A$ and B) represent the periods over which the oxygen consumption $\left(\mathrm{V}_{2}\right)$ was measured. Note that there is no significant fluctuation in incubator temperature during the periods of measurement as compared with the control periods. Inc. Mk. : incubator setting. 


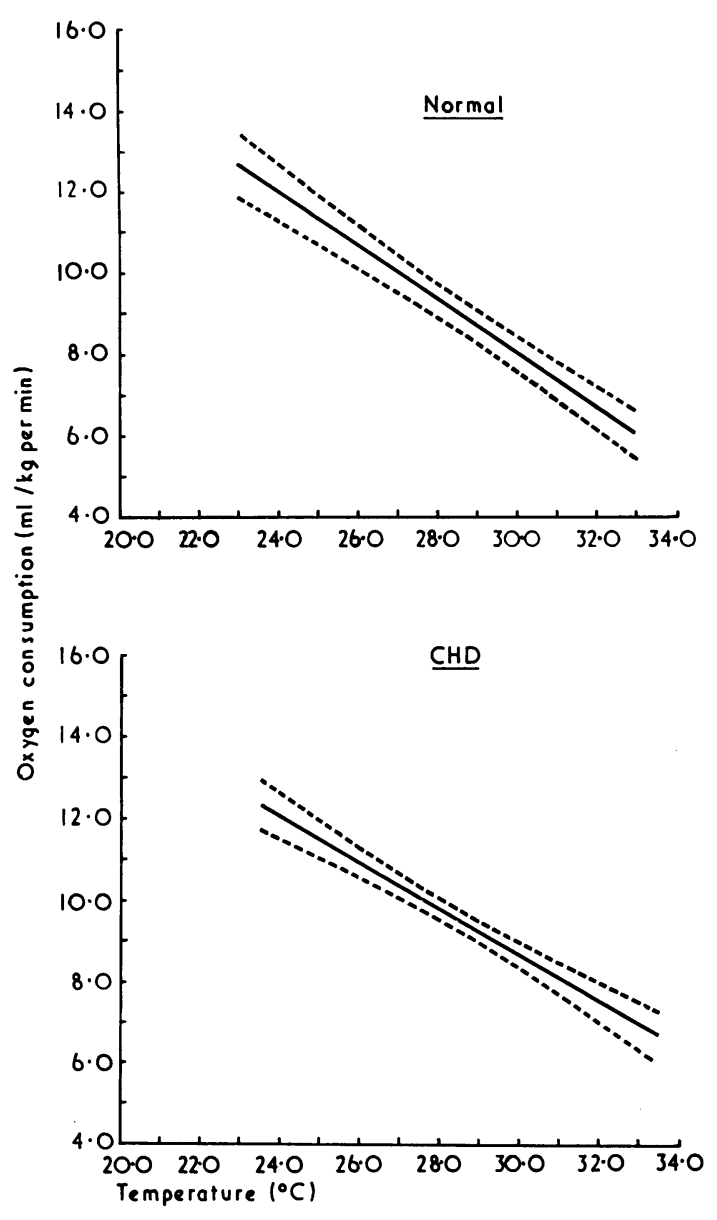

FIG. 3 The relation between the oxygen consumption and the environmental temperature. Ordinateoxygen consumption (ml/kg per min); abscissaenvironmental temperature $\left({ }^{\circ} \mathrm{C}\right)$. Top. Normal babies: The regression line is defined by the equation: Oxygen consumption $=-0.66 \times$ environmental temperature + 27.8. The interrupted lines are the confidence limits $(R=$ 0.87: analysis based on 52 observations). Bottom. Babies with congenital defect of the heart. The regression line is defined by the equation: Oxygen consumption $=-0.57 \times$ environmental temperature +25.7 . The interrupted lines are the confidence limits $(R=0.89$ : analysis based on 58 observations).

vestigation being 12 beats per minute for the former and 6 breaths per minute for the latter.

In all the babies investigated it was found that a reduction in the environmental temperature (i.e. incubator temperature) resulted in an increase in oxygen consumption. An example taken from a baby with congenital disease of the heart is illustrated in
Fig. 2. The oxygen consumption measured at $27^{\circ} \mathrm{C}$ was $29.1 \mathrm{ml} / \mathrm{min}$ (mean of 4 observations; range $28.0-29.4)$ and that at $29.5^{\circ} \mathrm{C}$ was $36.2 \mathrm{ml} / \mathrm{min}$ (mean of 4 observations; range 34.9-37.7). It will be noted that the rectal temperature remained unchanged during the study and that the environmental temperature did not fluctuate significantly during the period of measurement, in spite of drawing 80 to $100 \mathrm{l} / \mathrm{min}$ of room air through the hood.

Since all the babies investigated showed a trend that was qualitatively similar to that indicated above, the results from individual babies in each group were pooled to yield two sets of data which were subsequently subjected to regression analyses (Fig. 3). In both groups significant inverse relations were demonstrated $(P<0.05)$ between the oxygen consumption and the environmental temperature. The slopes of the two regression lines are not significantly different from each other $(P>0.05)$. The adjusted means (Snedecor and Cochran, 1967) for the babies with congenital diseases of the heart are significantly greater $(P<0.05)$ than in controls.

\section{Discussion}

The present investigation was undertaken to determine whether the oxygen consumption of infants with congenital diseases of the heart was related to the environmental temperature. Before considering the results of this study, it is necessary to examine the methods employed for the measurement of environmental temperature. The difficulties encountered in obtaining an accurate estimate of the true environmental temperature inside an incubator have been described in detail by Hey and Mount (1967). We are aware that the method used in this study for recording incubator temperatures would probably yield a value that would differ from that obtained by the more complex technique described by Hey and Mount (1967). However, in spite of this limitation, the present investigation has shown an inverse relation between the oxygen consumption and the environmental temperature in normal babies which is qualitatively similar to other published data (e.g. Adamsons, Gandy, and James, 1965; Hey, 1969). It must, therefore, be concluded that the methods employed in the present study are suitable for the purpose and that the relation demonstrated between oxygen consumption and the environmental temperature in the infants with congenital diseases of the heart is biologically valid.

These results have certain clinical implications. They bring into question the habit prevalent in many cardiac laboratories of predicting the oxygen con- 
sumption (for the purpose of calculating pulmonary and systemic blood flows) from tables (e.g. Rudolph and Cayler, 1958; LaFarge and Miettinen, 1970). It has already been shown in a study conducted under controlled laboratory conditions (Kappagoda et al., 1973) that the predicted values for oxygen consumption have a random error which is at least seven times that of measuring it. The finding that the oxygen consumption is related to the environmental temperature suggests that haemodynamic data calculated from predicted values of oxygen consumption should be treated with the utmost caution, since their inherent random error may be compounded in babies, by a systematic error introduced by differences in environmental temperature between one laboratory and another.

There has also been some speculation in published reports about the existence of a state of relative 'hypermetabolism' in children with congenital diseases of the heart as compared with normal children (Lees et al., 1965). In the context of the present investigation, this phenomenon would be revealed as a difference in the elevation of the two regression lines (Fig. 3), with the line for the babies with heart disease being above that of the control group, i.e. the adjusted means of the former would be significantly greater than that in the controls. Our investigation has indeed revealed such a statistical difference but much larger groups of infants would have to be studied before any biological significance could be attached to this observation.
The authors thank Dr. O. Scott and Dr. J. Buchanan for permission to study some of the patients under their care and the British Heart Foundation, Medical Research Council, and the Wellcome Trust for financial support.

\section{References}

Adamsons, K., Gandy, G. M., and James, L. S. (1965). The influence of thermal factors upon oxygen consumption of the new born human infant. Fournal of Pediatrics, 66, 495.

Hey, E. N. (1969). The relation between environmental temperature and oxygen consumption in the new-born baby. Fournal of Physiology, 200, 589.

Hey, E. N., and Mount, L. E. (1967). Heat losses from babies in incubators. Archives of Disease in Childhood, 42, 75.

Kappagoda, C. T., Greenwood, P., Macartney, F. J., and Linden, R. J. (1973). Oxygen consumption in children with congenital diseases of the heart. Clinical Science and Molecular Medicine, 45, 107.

Kappagoda, C. T., and Linden, R. J. (1972). A critical assessment of an open circuit technique for measuring oxygen consumption. Cardiovascular Research, 6, 589.

LaFarge, C. G., and Miettinen, O. S. (1970). The estimation of oxygen consumption. Cardiovascular Research, 4, 23.

Lees, M. H., Bristow, J. D., Griswold, H. E., and Olmsted, R. W. (1965). Relative hypermetabolism in infants with congenital heart disease and undernutrition. Pediatrics, 36, 183.

Rudolph, A. M., and Cayler, G. G. (1958). Cardiac catheterization in infants and children. Pediatric Clinics of North America, 5, 907.

Snedecor, G. L., and Cochran, W. G. (1967). Statistical Methods, 6th ed. Iowa State University Press, Ames, Iowa.

Requests for reprints to Dr. C. T. Kappagoda, Cardiovascular Unit, Department of Physiology, University of Leeds, Leeds LS2 9JT. 